\title{
Biochemia Medica celebrates its first impact factor
}

Ana-Maria Simundic, Marijana Miler, Nora Nikolac, Dubravka Cvoriscec, Elizabeta Topic

Editors, Biochemia Medica, Zagreb, Croatia

Key words: impact factor; journal; publication; editorial board

On behalf of the Editorial Board we proudly announce that Biochemia Medica has received its first Impact Factor. According to the recently released Thomson ISI Impact Factor list (1), the 2009 impact factor for Biochemia Medica is 0.660 . This impact factor comes as the great award for continuous efforts of the journal Editorial Board in the year when we celebrate the 5th anniversary of the life of the Journal in the new guise, after the major change of the journal content and design as well as the shift in editorial policy (2).

As nicely reviewed by prof. Ana Marusic, co-Editorin-chief of the Croatian Medical Journal, the development of the scientific journals in small scientific communities like Croatia, is hampered by a numerous factors, like financial resources, language barrier, the lack of high quality manuscripts and good reviewers and some other as well (3). Our editorial team has been doing a great job during the past several years and we take this opportunity to thank to all who contributed to this success. During these last five years, Biochemia Medica has been accepted for indexing in some major biomedical bibliographic databases $(4,5)$ and has been constantly improving the quality of the editorial work (6). Biochemia Medica has long recognized the importance of the statistical peer-review process $(7,8)$. We have therefore implemented a stati- stical review for all submitted manuscripts and are continuously publishing educational articles under the section Lessons in biostatistics, which has so far covered various topics like statistical hypothesis testing (9), meta-analyses (10), proper choice of the statistical test (11), etc. To find our own niche in this highly competitive and challenging international environment, besides covering all common relevant topics in clinical chemistry and laboratory medicine, we also cover issues like education (12), scientific publication in biomedicine (13-16), evidence-based research methodology (17-18), accreditation and quality (19-21) and many others.

Editorial work is voluntary, highly responsible and time-consuming. The only award for this highly demanding work is the quality of the journal, rating it receives from indexing databases and other indicators like citations, web page visits and number of article downloads. These figures are in continuous increase, indicating that it is worth the effort. Thank you!

We invite you all to continue assisting in this responsible job, by participating in the peer-review process, promoting the journal among your international colleagues, encouraging authors to submit their work to Biochemia Medica and sharing with us all your valuable comments and suggestions. 


\section{References}

1. ISI Web of Knowledge. Journal Citation reports. Available at: http://admin-apps.isiknowledge.com/JCR/JCR?RQ=REC ORD\&rank=1\&journal=BIOCHEM+MEDICA. Accessed September 10th 2010.

2. Topic E, Cvoriscec D. Biochemia Medica in the new guise. Biochem Med 2006;16:3-4.

3. Marusic A, Marusic M. Biochemia Medica - how to grow into a recognizable scientific journal? Biochem Med 2006;16:5-7.

4. Simundic. Biochemia Medica indexed. Biochem Med 2006;16:91-2.

5. Simundic AM, Topic E, Cvoriscec D. Biochemia Medica indexed in Science Citation Index Expanded and Journal Citation Reports/Science Edition citation databases. Biochem Med 2008;18:141-2.

6. Simundic AM, Topic E, Cvoriscec D. Biochemia Medica launches a new web page and an online manuscript submission system. Biochem Med 2010;20:125.

7. Petrovecki $M$. The role of statistical reviewer in biomedical scientific journal. Biochem Med 2009;19:223-30.

8. Simundic $A M$, Nikolac N. Statistical errors in manuscripts submitted to Biochemia Medica journal. Biochem Med 2009;19:294-300.

9. Ilakovac V. Statistical hypothesis testing and some pitfalls. Biochem Med 2009; 19:10-6.

10. Bartolucci AA. Describing and interpreting the methodological and statistical techniques in meta-analyses. Biochem Med 2009;19:127-36.
11. Marusteri $M$, Bacarea V. Comparing groups for statistical differences: how to choose the right statistical test? Biochem Med 2010;20:15-32.

12. Zanic Grubisic T. Education of Masters of Science in Medical Biochemistry at the Faculty of Pharmacy and Biochemistry, University of Zagreb: How did we fit in the Bologne process. Biochem Med 2008;18:143-53.

13. Zima T. Impact factor and evaluation of scientific papers or teams. Biochem Med 2008; 18:5-6.

14. Jokic M. H-index as a new scientometric indicator. Biochem Med 2009;19:5-9.

15. Bilic-Zulle L. Scientific integrity - the basis of existence and development of science. Biochem Med 2007;17:143-50.

16. Bilic-Zulle. Responsible writing in science. Biochem Med 2010;20:279-81.

17. Puljak L, Rako D. Enhancing medical practice in Croatia through The Cochrane Collaboration. Biochem Med 2009; 19:260-5.

18. Sambunjak $D$, Puljak L. Cochrane systematic review as a PhD thesis: an alternative with numerous advantages. Biochem Med 2010;20:319-26.

19. Ricos C, Perich C, Minchinela J, Alvarez V, Simon M, Biosca $C$, et al. Application of biological variation - a review. Biochem Med 2009; 19:250-9.

20. Gasljevic V. Method validation and measurement uncertainty. Biochem Med 2010;20:57-63.

21. Challand GS, Li P. The assessment of interpretation of test results in laboratory medicine. Biochem Med 2009;19:146-53. 